\title{
Adsorption and Interaction of Carbon Dioxide and Water on the Molybdenum Oxide Surface
}

\author{
Galina S. Grigorkina ${ }^{1}$, Aljona G. Ramonova ${ }^{1}$, David D. Kibizov ${ }^{1}$, Vladislav B. Zaalishvili ${ }^{2}$, \\ Ol'ga G. Burdzieva ${ }^{2}$, Evgenij N. Kozyrev ${ }^{3}$, Markus Wilde ${ }^{4}$, Shohei Ogura ${ }^{4}$, Katzuyuki Fukutani ${ }^{4}$, \\ Tamerlan T. Magkoev, ${ }^{1 *}$ \\ ${ }^{1}$ Department of Physics, North Ossetian State University, Russia \\ ${ }^{2}$ Geophysical Institute of the Vladikavkaz Scientific Center of Russian Academy of Sciences, Russia \\ ${ }^{3}$ North Caucasian Institute of Mining and Metallurgy(NCIMM), State Technological University(STU), Russia \\ ${ }^{4}$ Institute of Industrial Science, The University of Tokyo, Komaba, Japan
}

Copyright $\bigcirc 2017$ by authors, all rights reserved. Authors agree that this article remains permanently open access under the terms of the Creative Commons Attribution License 4.0 International License

\begin{abstract}
By means of X-ray and ultraviolet photoelectron spectroscopy (XPS, UPS), atomic force microscopy (AFM) and reflection-absorption infrared spectroscopy (RAIRS) it is shown that methanol is formed from carbon dioxide and water on the surface of reduced molybdenum oxide substrate $\mathrm{MoO}_{\mathrm{x}}(\mathrm{x}<2)$ under pulsed laser irradiation at photon energy of $6.4 \mathrm{eV}$, pulse duration $9 \mathrm{~ns}$ and laser fluence of $4 \mathrm{~mJ} / \mathrm{cm}^{2}$. The key factor is $\mathrm{MoO}_{\mathrm{x}}$ defect enhanced photoinduced substrate mediated $\mathrm{CO}_{2}$ and $\mathrm{H}_{2} \mathrm{O}$ bond activation, leading to formation of reaction intermediates: $\mathrm{CH}_{2} \mathrm{O}_{2} \rightarrow \mathrm{CH}_{2} \mathrm{O} \rightarrow \mathrm{O}-\mathrm{CH}_{3}$, forming finally methanol.
\end{abstract}

Keywords Surface Reaction, Model Catalysts, Metal Oxides, Carbon Dioxide, Water, Surface Science Techniques

\section{Introduction}

Synthesis of methanol as a top ten industrial products deserves considerable interest from the scientific and technological viewpoints. Particularly important is its synthesis from the waste gases like carbon dioxide [1]. In this regard the main challenge is to develop corresponding new efficient catalysts which moreover do not contain precious metals, like Pt, $\mathrm{Au}, \mathrm{Pd}$, Ir. In this regard, the $\mathrm{Cu} / \mathrm{ZnO}$ catalyst system is widely used for several important industrial processes, which include the synthesis of methanol, as one of the top-ten industrial products, and the forward and reverse water-gas-shift reactions [2,3]. The system is complicated with the active catalyst being a coprecipitate of $\mathrm{ZnO}$ and $\mathrm{Cu}$ on an $\mathrm{Al}_{2} \mathrm{O}_{3}$ support [4]. Different works have looked at the various components of this system in order to illuminate their role in the catalytic process. These include investigations into the contribution of the copper nanoparticles $[5,6]$, the various facets of the $\mathrm{ZnO}$ substrate [7-9], the oxidation state of $\mathrm{Cu}$ [10-13] and alloying of $\mathrm{Cu}$ with $\mathrm{Zn}$ [14]. Despite of the very extensive research of $\mathrm{CO}_{2}$ surface chemistry there are still some unresolved problems relating, for instance, to exact determination of the reaction sites and linking the nature of this sites to specific reaction pathways $[2,14]$. To address the latter issue in view of metal/oxide model catalysts, one can use easy and controllably reducible oxides providing a set of metal ionic charges: Metal ionicity is considered to be an important factor in molecular surface reaction [15]. In this regard, $\mathrm{MoO}_{3}$ is promising support because of the possibility of controllable reduction of $\mathrm{Mo}^{+6}$ to $\mathrm{Mo}^{+5}, \mathrm{Mo}^{+4}, \mathrm{Mo}^{+3}, \mathrm{Mo}^{+2}$.

The present work deals with the design of molybdenum oxide $\mathrm{MoO} 2$ with a specific density of anionic vacancies for methanol synthesis from carbon dioxide and water. The choice of molybdenum oxide is motivated by the fact that this material, as stated above, is easily tunable in terms of defect nature and density, for instance by electron and ion bombardment or thermal treatment. The defects, in turn, considerably affect the catalytic behavior of the oxide.

\section{Materials and Methods}

Investigations have been carried out in ultra-high vacuum chamber (base pressure: $10^{-10}$ Torr) by means of atomic force microscopy (AFM), reflection-absorption infrared spectroscopy (RAIRS), X-ray and ultraviolet photoelectron spectroscopy (XPS, UPS) using $\mathrm{Al} \mathrm{K}_{\alpha}(1486.6 \mathrm{eV})$ and He II $(40.8 \mathrm{eV})$ irradiation, respectively [16,17]. RAIRS was designed in configuration, shown in Fig. 1, using p-polarized infrared beam. In this configuration the technique is sensitive to the molecular vibrations oriented along the surface normal. Amplification of electric field of incident and reflected 
waves at the surface plane enhances sensitivity of the technique at grazing incident and reflection angles. In the present configuration they were 83 degrees. A Mo(110) crystal serving as a substrate was mounted on a holder, which enabled cooling and heating of a sample to 90 and $2400 \mathrm{~K}$, respectively. The sample was cleaned to remove foreign admixtures by the standard procedure of high-temperature annealing in an atmosphere of, first, oxygen and, then, hydrogen. Molybdenum oxide film was grown on Mo(110) bulk crystal by its oxidation in an oxygen ambient at partial pressure of $10^{-6}$ Torr and at a substrate temperature ranging from 1000 to $1300 \mathrm{~K}$. According to previous results [18], thin surface oxide $\mathrm{MoO} 2(010)$ film grows at a substrate temperature of $1300 \mathrm{~K}$, while thicker three-dimensional film grows after reducing the substrate temperature to $1000 \mathrm{~K}$. Thick film develops into a periodically faceted surface with nanowirelike structures composed of $\mathrm{MoO}_{2}(021)$ and (02-1) faces. The corresponding AFM image of $\mathrm{MoO}_{2}$ as-grown thick film and the XPS spectra characterizing transition from $\mathrm{Mo}(110)$ substrate to thick $\mathrm{MoO} 2$ film and reduced $\mathrm{MoO}_{\mathrm{x}}$ $(x<2)$ are shown in Figs. 2 and 3, respectively. The fact that the XPS spectrum contains no lines associated with Mo (110) evidences that the oxide film fully covers the surface of Mo (110) and has a sufficient thickness for retaining photoelectrons from the substrate. Taking into account the $1200 \mathrm{eV}$ kinetic energy of these electrons, one can consider that the thickness of the oxide film is no less than $7 \mathrm{~nm}$.

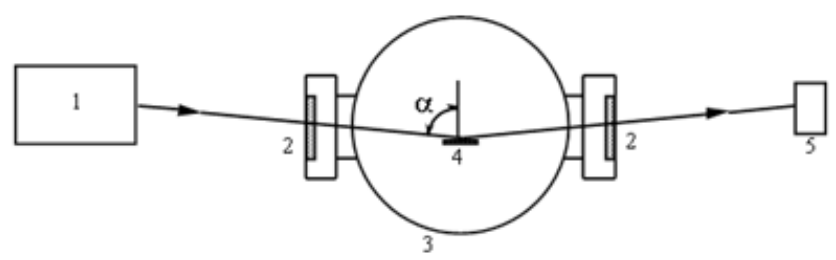

Figure 1. RAIRS scheme. 1-interferometer, 2-CaF 2 windows, 3-UHV chamber, 4-sample, 5-CdHgTe detector

To reduce the as-grown $\mathrm{MoO}_{2}$ oxide it was bombarded by Ar ions at energy of $1 \mathrm{keV}$ and current density of $10 \mathrm{~mA} / \mathrm{cm}^{2}$ to produce oxygen vacancies of approximately of $1 / 4$ of their initial concentration in surface region. It can be seen in Fig. 3 that the exposure to the ions results in a partial reduction of the oxide, which is manifested in the appearance of new low-energy photoelectron signals. Qualitative analysis of how the intensity of these lines varies under the ion bombardment indicates that about one-quarter of anionic vacancies are formed relative to the initial density of oxygen ions. Additionally, as seen in Fig 2, ion bombardment causes smoothing of rough relief of the surface still leaving surface roughness at nanometer scale. After cooling the sample down to $90 \mathrm{~K}$ the carbon dioxide was admitted into the vacuum chamber up to $10^{-8}$ Torr, followed by subsequent inlet of water until the base pressure reached $10^{-6}$ Torr. Further, the sample was irradiated by laser light from pulsed ArF eximer laser (photon energy: $6.4 \mathrm{eV}$, fluence: $4 \mathrm{~mJ} / \mathrm{cm}^{2}$, pulse duration $9 \mathrm{~ns}$, repetition rate: $10 \mathrm{~Hz}$ ).
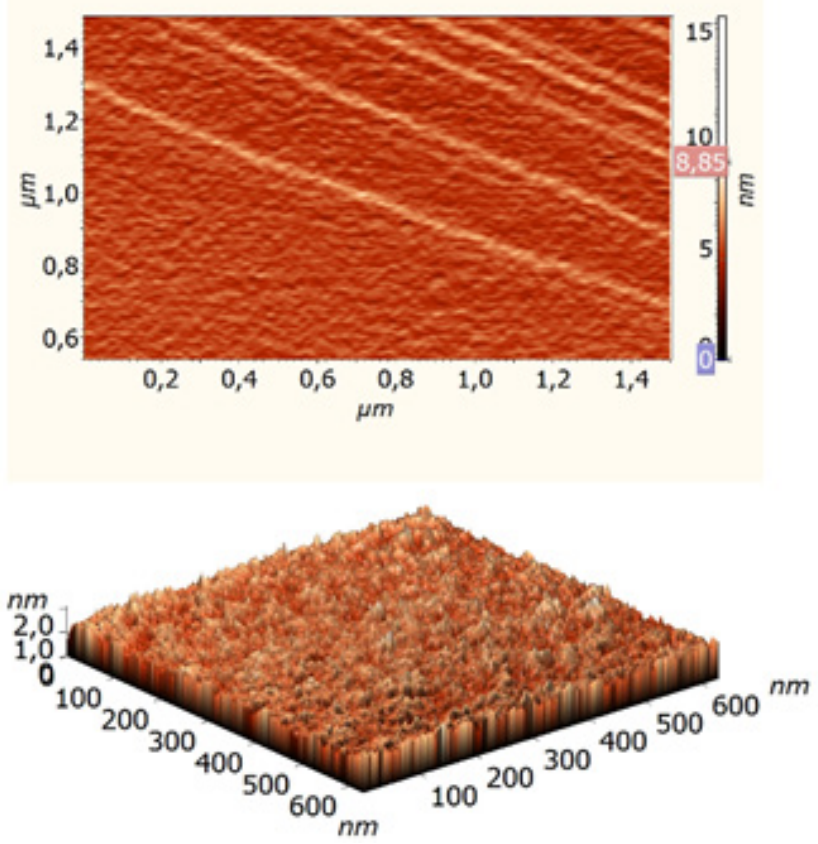

Figure 2. AFM image of $\mathrm{MoO}_{2} 11 \mathrm{~nm}$ thick film on $\mathrm{Mo}(110)$ crystal before (upper image) and after Ar ion bombardment (lower image).

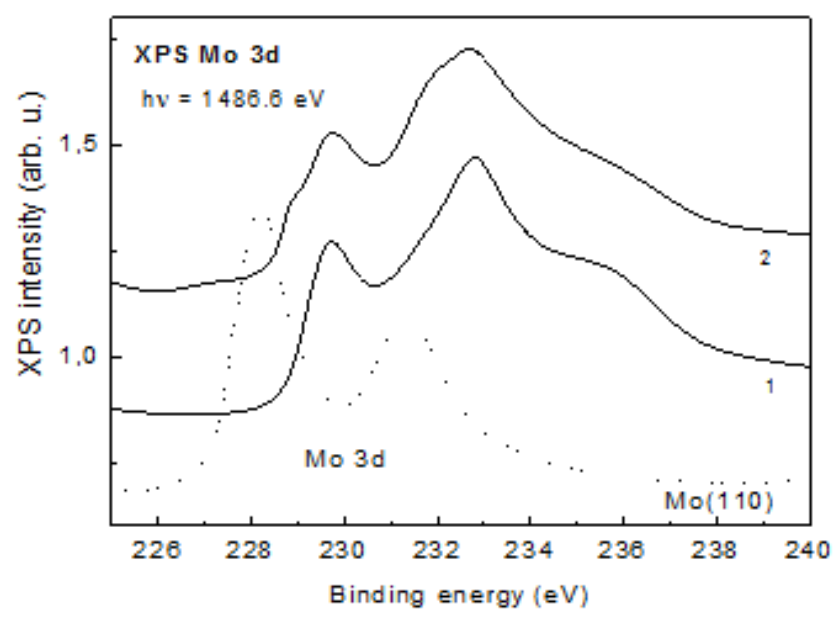

Figure 3. XPS spectra of $\mathrm{Mo}(110)$ crystal, $\mathrm{MoO}_{2} 11 \mathrm{~nm}$ thick film (1) and reduced by about $25 \%$ of oxygen density the $\mathrm{MoO}_{\mathrm{x}}(2)$.

\section{Results and Discussion}

The UPS spectrum of $\left(\mathrm{CO}_{2}+\mathrm{H}_{2} \mathrm{O}\right) / \mathrm{MoO}_{\mathrm{x}}$ after laser irradiation for $5 \mathrm{~min}$ and subtracted from UPS of bare $\mathrm{MoO}_{\mathrm{x}}$ is shown in Fig. 4 (curve 1). To account for the observed spectral features this spectrum is compared with the spectrum of multilayer methanol film (curve 2). The qualitative agreement between these two spectra indicates that methanol molecules are formed when the $\left(\mathrm{CO}_{2}+\right.$ $\left.\mathrm{H}_{2} \mathrm{O}\right) / \mathrm{MoO}_{\mathrm{x}}$ system kept at low temperature is exposed to photons. Some observed discrepancy between these two spectra is presumably due to the fact that along with the methanol there are some reaction intermediates at the surface. 
Nevertheless, the close intensities of the main photoelectron lines in spectra 1 and 2 demonstrate that carbon dioxide and water molecules are converted to methanol to a noticeable extent and a corresponding condensed layer is formed. It should be noted that the characteristic spectrum of $\mathrm{CH}_{3} \mathrm{OH}$ is hardly observed in the absence of photons. Similarly, using a stoichiometric $\mathrm{MoO}_{2}$ film as a substrate under the same experimental conditions does not lead, either, to formation of spectral features characteristic of methanol.

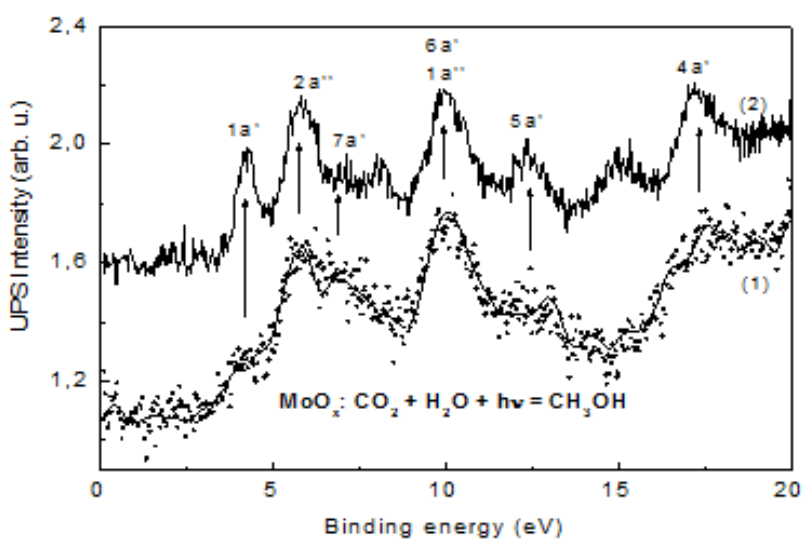

Figure 4. Comparison of UP spectrum of methanol multilayer condensed film on $\mathrm{MoO}_{\mathrm{x}}(2)$ with the spectrum obtained after exposure of $\mathrm{MoO}_{\mathrm{x}}$ in an ambient of $\mathrm{CO}_{2}$ and $\mathrm{H}_{2} \mathrm{O}$ to photons (1).

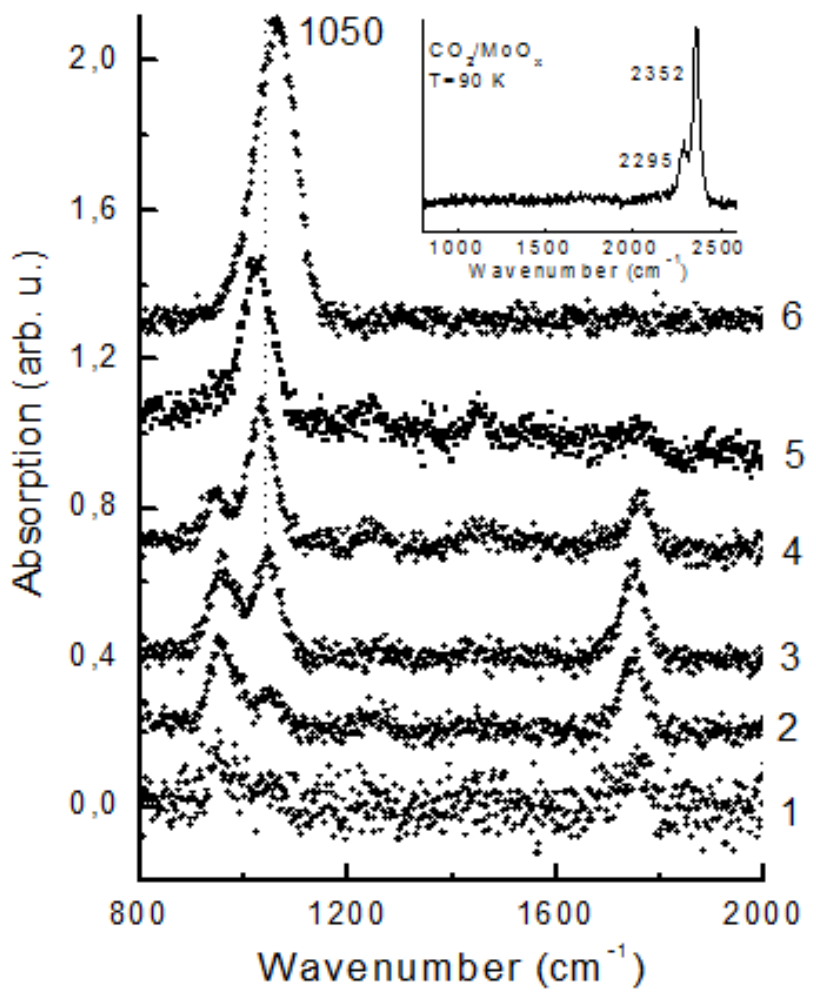

Figure 5. Figure 5. Infrared spectra in $\mathrm{CO}$ stretch region during laser irradiation of mixture of $\mathrm{CO}_{2}$ and $\mathrm{H}_{2} \mathrm{O}$ on the surface of MoOx at $90 \mathrm{~K}(1-5)$. Irradiation time, min: 1-1, 2-2, 3-3, 4-4, 5-6. Curve 6 corresponds to condensed methanol overlayer. IR spectrum of $\mathrm{CO}_{2}+\mathrm{H}_{2} \mathrm{O}(500 \mathrm{~L}+500 \mathrm{~L})$ ) adsorbed on MoOx at $90 \mathrm{~K}$ is shown in an inlay.
In this context, it should be assumed that the key factors responsible for the formation of methanol from carbon dioxide and water are the presence of anionic vacancies and exposure to photons. The known mechanisms of adsorption of $\mathrm{CO}_{2}$ and $\mathrm{H}_{2} \mathrm{O}$ molecules on the surface of oxides can be invoked as a possible explanation of the observed effect [4, 5]. For example, it has been well established that the $\mathrm{CO}_{2}$ molecule is adsorbed on the stoichiometric metal oxide surface to yield carbonate-like compounds via formation of bonds between an oxygen atom of the molecule and an oxygen atom of the substrate and between the carbon and the substrate metal. At the same time, in the presence of anionic vacancies, the predominant adsorption configuration is that in which an anionic vacancy is filled by an oxygen atom of the carbon dioxide molecule. In both cases, the charge transfer from the substrate to the $\pi$-orbital of the molecule results in the molecular axis of $\mathrm{CO}_{2}$ becoming deformed and the unstable configuration forming. The probability of formation of such a negatively charged configuration becomes higher due to filling of anionic vacancies by photoexcited electrons. When an $\mathrm{H}_{2} \mathrm{O}$ molecule is adsorbed on the molybdenum oxide surface, it dissociates into $\mathrm{H}^{+}$and $\mathrm{OH}^{-}$[4]. In the presence of an excess charge, which is generated in the given case via photoexcitation of carriers in the substrate, there occurs effective formation of the formate ion $\mathrm{CHOO}^{-}$, which, interacting with the hydrogen ion released via $\mathrm{H}_{2} \mathrm{O} \rightarrow \mathrm{H}^{+}+\mathrm{OH}^{-}$, yields $\mathrm{CHOOH}$. It has been found that further conversion of $\mathrm{CHOOH}$ in the presence of an excess amount of hydrogen ions generated via dissociation of $\mathrm{H}_{2} \mathrm{O}$, enhanced by photons and substrate defects, occurs by the $\mathrm{CHOOH} \rightarrow \mathrm{CH}_{2} \mathrm{O} \rightarrow \mathrm{CH}_{3} \mathrm{O} \rightarrow$ $\mathrm{CH}_{3} \mathrm{OH}$ mechanism [3]. In this case, accommodation by the substrate of hydroxide ions formed in the reaction $\mathrm{H}_{2} \mathrm{O} \rightarrow \mathrm{H}^{+}$ $+\mathrm{OH}^{-}$is necessary, which is enabled by the formation of oxy-hydroxide ions of the metal, $\mathrm{MoO}(\mathrm{OH})^{-}$. These complexes are formed with the highest probability on the stoichiometric surface of the oxide [4]. This accounts for the fact that, for the above transformations to occur, molybdenum oxide should be only partly nonstoichiometric, while a certain part of the substrate surface should retain the $\mathrm{MoO}_{2}$ stoichiometry. Otherwise, one can expect quite high poisoning of the substrate by hydroxylation of active sites.

Formation of certain reaction intermediates is evidenced by reflection infrared absorption spectra recorded after successively increasing laser irradiation time (Fig. 5). It is seen that initially methoxy and formaldehyde, characterized by $\mathrm{C}-\mathrm{O}$ stretch vibration wavenumbers of $1000 \mathrm{~cm}^{-1}$ and $1725 \mathrm{~cm}^{-1}$, respectively, are formed. At higher irradiation time these species are almost totally converted to methanol, characterized by the wavenumber of $1050 \mathrm{~cm}^{-1}$. An apparent red shift of the band in curve 5, compared to the band of multilayer condensed methanol (curve 6) and a trace intensity of the band at $1725 \mathrm{~cm}^{-1}$, indicates that there are still some intermediates, like methoxy and formaldehyde, remaining at the surface. This also explains some observed discrepancy in UPS spectra of $\left(\mathrm{CO}_{2}+\mathrm{H}_{2} \mathrm{O}\right)$ irradiated film and condensed overlayer of methanol (Fig. 4). At the same 
time, qualitative analysis of infrared intensities implies that the amount of reaction intermediates is at the level not exceeding $10 \%$. Thus, $\mathrm{MoO}_{2}$ with submonolayer concentration of anionic vacancies (c.a. $25 \%$ ) is an efficient model catalyst for methanol photosynthesis from carbon dioxide and water. In an inlay of Fig. 5 there is infrared spectrum of coadsorbed carbon dioxide and water on reduced molybdenum oxide cooled down to $90 \mathrm{~K}$ at exposure of each gas of $500 \mathrm{~L}$. The spectrum consists of IR features at $2295 \mathrm{~cm}^{-1}$ and $2352 \mathrm{~cm}^{-1}$, corresponding to $\mathrm{C}-\mathrm{O}$ intramolecular vibrations of $\mathrm{CO}_{2}$. There is no evidence of the features around $1000-1200 \mathrm{~cm}^{-1}$, characteristic for methoxy and formaldehyde, suggesting that there is no reaction between $\mathrm{CO}$ and $\mathrm{H}_{2} \mathrm{O}$. It means, therefore, that the effect of photons is a key point in carbon dioxide and water conversion to methanol on reduced molybdenum oxide surface.

\section{Conclusions}

By means of surface sensitive techniques it has been shown that methanol is effectively formed from carbon dioxide and water in an ultrahigh vacuum on the surface of molybdenum oxide $\mathrm{MoO}_{2}$ with a submonolayer concentration of anionic vacancies at a substrate temperature of $90 \mathrm{~K}$ under the action of laser light with a photon energy of $6.4 \mathrm{eV}$. The key role is played by the processes of adsorption and bond activation of $\mathrm{CO}_{2}$ and $\mathrm{H}_{2} \mathrm{O}$ molecules on surface defects of the substrate enhanced by the exposure to photons.

\section{Acknowledgements}

The reported study was funded by Russian Fund for Basic Research (RFBR) according to research project \# 16-02-00138-a and Goszadanie SOGU of Russian Ministry of Education and Science (project \# 3.9281.2017 ) and RFBR-Japan Society for the Promotion of Science (JSPS) grant \# 17-52-50010 JaF-a. Technology maintenance and technical support was provided by FTP NCIMM (STU), PNIER, and unique ID RFMEFI57715X0196.

\section{REFERENCES}

[1] U. Burghaus. Adsorption of carbon dioxide on clean surfaces at ultrahigh vacuum, Progr. Surf. Sci. Vol. 89, 161-217, 2014.

[2] M. Saito, K. Murata. Development of high performance $\mathrm{Cu} / \mathrm{ZnO}$-based catalysts for methanol synthesis and the water-gas shift reaction, Catal. Surv. Asia Vol. 8, 285-294, 2004.
[3] A. Karelovic, A. Bargibant, C. Fernández, P. Ruiz. Effect of the structural and morphological properties of $\mathrm{Cu} / \mathrm{ZnO}$ catalysts prepared by citrate method on their activity toward methanol synthesis from $\mathrm{CO}_{2}$ and $\mathrm{H}_{2}$ under mild reaction conditions, Catal. Today Vol. 197, 109-118, 2012.

[4] G. Ertl, H. Knotzinger, J. Weitkamp. Handbook of Heterogeneous Catalysis. VCH, Weinheim, 4270 p., 2008.

[5] L.V. Koplitz, O. Dulub, U. Diebold. STM study of copper growth on $\mathrm{ZnO}(0001)-\mathrm{Zn}$ and $\mathrm{ZnO}(0001)-\mathrm{O}$ surfaces, J. Phys. Chem. Vol. B 107, 10583-10590, 2003.

[6] M. Kroll, U. Köhler. Small Cu-clusters on $\mathrm{ZnO}(0001)-\mathrm{Zn}$ : Nucleation and annealing behavior, Surf. Sci., Vol. 601, 2182-2188, 2007.

[7] B. Meyer, D. Marx. Density-functional study of the structure and stability of $\mathrm{ZnO}$ surfaces, Phys. Rev. Vol. B 67, 03540-03545, 2003.

[8] M. Schiek, K. Al-Shamery, M. Kunat, F. Traeger, C. Wöll. Water adsorption on the hydroxylated $\mathrm{H}-(1 \times 1) \mathrm{O}-\mathrm{ZnO}(0001)$ surface, Phys. Chem. Chem. Phys. Vol. 8, 1505-1512, 2006.

[9] C. Wöll. The chemistry and physics of zinc oxide surfaces, Prog. Surf. Sci., Vol. 82, 55-120, 2007.

[10] O. Dulub, M. Batzill, U. Diebold. Growth of copper on single crystalline ZnO: Surface study of a model catalyst, Top. Catal., Vol. 36, 65-76, 2005.

[11] P. Lazcano, M. Batzill, U. Diebold, P. Haberle. Oxygen adsorption on $\mathrm{Cu} / \mathrm{ZnO}(0001)-\mathrm{Zn}$, Phys. Rev. Vol. B 77, 035435-035439, 2008.

[12] X.Q. Dai, H.J. Yan, J.L. Wang, Y.M. Liu, Z. Yang, M.H. Xie. The effect of $\mathrm{Cu}$ on $\mathrm{O}$ adsorption on a $\mathrm{ZnO}(0001)$ surface: a first-principles study, J. Phys. Condens. Matter, Vol. 20, 095002-095007, 2008.

[13] K. Ozawa, Y. Oba, K. Edamoto. Formation and characterization of the $\mathrm{Cu}_{2} \mathrm{O}$ overlayer on Zn-terminated ZnO(0001), Surf. Sci., Vol. 603, 2163-2170, 2009.

[14] M. Behrens, F. Studt, I. Kasatkin, S. Kühl, M. Hävecker, F. Abild-Pederson, S. Zander, F. Girgsdies, P. Kurr, B.L. Kniep, M. Tovar, R. W. Fischer, J.K. Nørskov, R. Schlögl. The active site of methanol synthesis over $\mathrm{Cu} / \mathrm{ZnO} / \mathrm{Al}_{2} \mathrm{O}_{3}$ industrial catalysts. Science, Vol. 33, 893-897, 2012.

[15] H.-J. Freund, M.W. Roberts. Surface chemistry of carbon dioxide. Surf. Sci. Reports, Vol. 25, 225-273, 1996.

[16] I.V. Tvauri, B.E. Gergieva, V.D. Magkoeva, G.S. Grigorkina, A.P. Bliev, O.G. Ashkhotov, V.A. Sozaev, K. Fukutani, T.T. Magkoev. Carbon monoxide oxidation on lithium fluoride supported gold nanoparticles: A significance of F-centers. Solid State Commun., Vol. 213, 42-45, 2015.

[17] T.T. Magkoev. Interaction of carbon monoxide and oxygen on the surface of inverse titania/Au model catalyst, Surf. Sci., Vol. 601, 3143-3148, 2007.

[18] K. Radican, N. Berdunov, I.V. Shvets. Studies of the periodic faceting of epitaxial molybdenum oxide grown on Mo(110), Phys. Rev., Vol. B77, 085417, 2008. 